\title{
Detection of Quantitative Trait Loci in Danish Holstein Cattle Affecting Clinical Mastitis, Somatic Cell Score, Udder Conformation Traits, and Assessment of Associated Effects on Milk Yield
}

\author{
M. S. Lund, ${ }^{1}$ B. Guldbrandtsen, A. J. Buitenhuis, B. Thomsen, and C. Bendixen \\ University of Aarhus, Faculty of Agricultural Sciences, Department of Genetics \& Biotechnology, Research Centre Foulum, DK-8830 Tjele, \\ Denmark
}

\section{ABSTRACT}

The aim of this study was to 1) detect QTL across the cattle genome that influence the incidence of clinical mastitis and somatic cell score (SCS) in Danish Holsteins, and 2) characterize these QTL for pleiotropy versus multiple linked quantitative trait loci (QTL) when chromosomal regions affecting clinical mastitis were also affecting other traits in the Danish udder health index or milk production traits. The chromosomes were scanned using a granddaughter design where markers were typed for 19 to 34 grandsire families and 1,373 to 2,042 sons. A total of 356 microsatellites covering all 29 autosomes were used in the scan. Among the acrossfamily regression analyses, 16 showed chromosomewide significance for the primary traits incidence of clinical mastitis in first (CM1), second (CM2), and third (CM3) lactations, and SCS. Regions of chromosomes 5, $6,9,11,15$, and 26 were found to affect $\mathrm{CM}$ and regions of chromosomes 5, 6, 8, 13, 22, 23, 24, and 25 affected SCS. Markers on chromosomes 6, 11, 15, and 26 can be used to perform marker-assisted selection on CM without a direct negative selection on milk yield, because no effects were detected on the milk traits. Comparing multi-trait models assuming either a pleiotropic QTL affecting 2 traits or 2 QTL each affecting 1 trait gave some evidence to distinguish between these models. For Bos taurus autosome 5, the most likely models were a pleiotropic QTL affecting CM2, CM3, and SCS, and a linked QTL affecting fat yield index. For Bos taurus autosome 9, the most likely model is a pleiotropic QTL affecting CM1 and CM2 at approximately $8 \mathrm{cM}$.

Key words: quantitative trait locus, mastitis and milk yield, udder conformation, Bos taurus

Received April 17, 2007.

Accepted May 20, 2008.

${ }^{1}$ Corresponding author: mogens.lund@agrsci.dk

\section{INTRODUCTION}

Mastitis is a prime candidate for genetic improvement through marker-assisted selection. Mastitis is the most costly disease in dairy production, its heritability is low (Heringstad et al., 2000), it is difficult to record, and there is an undesirable genetic correlation to production traits (Simianer et al., 1991; Pösö and Mantysaari 1996; Lund et al., 1999). Considerable efforts have therefore been put into identification of QTL associated with mastitis. Even though the main objective in breeding schemes is to reduce cases of clinical mastitis (CM), recordings are not generally available. Therefore, most studies have focused on SCS as an indirect measure of mastitis (Heyen et al., 1999; Schrooten et al., 2000, 2004; Kuhn et al., 2003; Ashwell et al., 2004; Khatkar et al., 2004; Longeri et al., 2006; Sugimoto et al., 2006), primarily because QTL mapping in dairy cattle is largely limited to traits that are recorded in the breeding schemes of commercial populations. Only the Nordic countries have well-established national registration systems for health traits. Scans in Norway (Klungland et al., 2001), Finland (Schulman et al., 2004), and Sweden (Holmberg and Andersson-Eklund, 2004) included SCS and CM. Schulman et al. (2004) detected a QTL on Bos taurus autosome (BTA) 18 for both SCS and CM, whereas Holmberg and AnderssonEklund (2004) detected QTL for both CM and SCS on BTA9 and BTA11. In general, the overlap in the results on QTL affecting CM and SCS was low unless cofactor analysis was performed. This could be because these studies have relatively low power to identify QTL, in which case the power to obtain significant results for both CM and SCS is low, even with a pleiotropic QTL affecting both traits. This is supported by the finding of Schulman et al. (2004) that when cofactor analysis was applied, the concordance was much greater. Even though cofactor analysis applied this way has serious problems with controlling the type I error, as shown in Sahana et al. (2006), the results are a strong indication that if less-stringent thresholds are applied, the effects of a pleiotropic QTL are more likely to be identified for 
both CM and SCS. Another reason that a particular region only affects 1 trait is that the traits reflect different aspects of udder health.

The genetic correlation between SCS and CM has been found to be in the range of 0.3 to 0.8 , with an average of 0.6 (Heringstad et al., 2000). Measuring CM in early lactation and using a measure of SCS deviance from a normal curve, the correlation was 0.8 under Danish conditions (Lund et al., 1999). The studies indicate that SCS and CM are both measures of udder health, but do not have the same genetic basis. They may reflect different aspects of defense mechanisms against pathogens. In particular, elevated SCS indicates increased SCC for a longer period, such as during a Staphylococcus aureus infection, whereas infections of short duration, such as those by Escherichia coli, are better detected using CM. Nevertheless, the relatively high genetic correlation implies that a fraction of significant QTL should affect both SCS and CM. However, in studies where only SCS is studied there is no way of knowing whether a particular SCS QTL has a pleiotropic effect on CM. A genome scan for QTL affecting CM in a large granddaughter design for Holstein would be beneficial to verify whether the many QTL for SCS identified in Holstein also affect CM.

In Denmark, breeding for improved mastitis resistance is performed using a multi-trait index combining information on treatment for mastitis in first, second, and third lactations and the correlated indicator traits SCS, dairy form, and udder conformation. It is important to dissect the effect of a given QTL to include the QTL information with the proper weight on the different traits in a multi-trait BLUP evaluation, because a given QTL may affect only some of the traits.

Mastitis resistance is genetically correlated to milk production traits, which are the most important traits economically. It is therefore essential to investigate if a given QTL that increases resistance to mastitis also has an effect on milk production traits. If a chromosomal region is found to affect both traits, it is important to know if the effects are caused by 1 pleiotropic QTL affecting both traits or result from linked genes each affecting 1 trait. In the latter situation, one may select for recombinant animals and thereby break unfavorable correlations due to the linkage.

The aim of the study was 1) to detect QTL across the cattle genome that influence the incidence of clinical mastitis and SCS in Danish Holstein, and 2) to characterize these QTL for pleiotropy vs. multiple linked QTL when chromosomal regions affecting clinical mastitis also affected other traits in the Danish udder health index or milk production traits.

\section{MATERIALS AND METHODS}

\section{Animals}

A total genome scan was carried out in the Danish Holstein population. Marker and phenotypic data were collected according to a granddaughter design (Weller et al., 1990). Chromosomes 2, 4, 5, 6, 9, 12, 13, 19, 20, $22,23,24$, and 25 were analyzed in 19 grandsires and 1,592 sons; chromosome 17 in 20 families; chromosome 14 in 24 grandsire families; chromosome 28 in 33 families; and chromosomes 1, 3, 7, 8, 10, 11, 15, 16, 18, 21, 26, 27, and 29 in 34 grandsires and 2,297 sons. Numbers of sons per sire ranged from 20 to 106, with an average family size of 84 for the 19 families and 68 for the 34 families. Sires and their sons were genotyped for marker information whereas phenotypic records were taken from granddaughter performances.

\section{Markers and Maps}

Markers and their positions were chosen from the Web site of the Meat Animal Research Center (http:// www.marc.usda.gov/genome/genome.html). All 29 autosomes were covered by using 356 microsatellite markers with an average marker spacing of $8.60 \mathrm{cM}$. Markers and positions are given in Table 1. The PCR reactions were analyzed on an automated sequence analyzer (ABI 3730 DNA Analyzer, Applied Biosystems, Foster City, CA) and the alleles were assigned with the GeneMapper software, version 3.7 (Applied Biosystems). The software GDQTL (B. Guldbrandtsen, personal communication) was used to check the genotype data for segregation distortion, to check the observed rate of recombinations between markers against expectations based on public map positions, and for construction of haplotypes (results not shown).

\section{Phenotypic Data Udder Health Traits}

The data used were EBV for traits of sons; BLUP were calculated in a model ignoring family structure between sires. Predictions were calculated in singletrait models such that information from correlated traits does not affect them. Fixed effects in the models were class effects of herd-year-season, year-month, and calving age (first parity only). The random effects were sire and residuals. For clinical mastitis, EBV were calculated using a model with the risk periods being from $10 \mathrm{~d}$ before to $305 \mathrm{~d}$ after first calving (CM1), second calving (CM2), and third calving (CM3). The number of records was 2,008 for CM1; 1,996 for CM2; and 1,778 for CM3. Mastitis in each of these periods is recorded 
Table 1. Distribution of the markers across the chromosomes (Bos taurus autosomes, BTA)

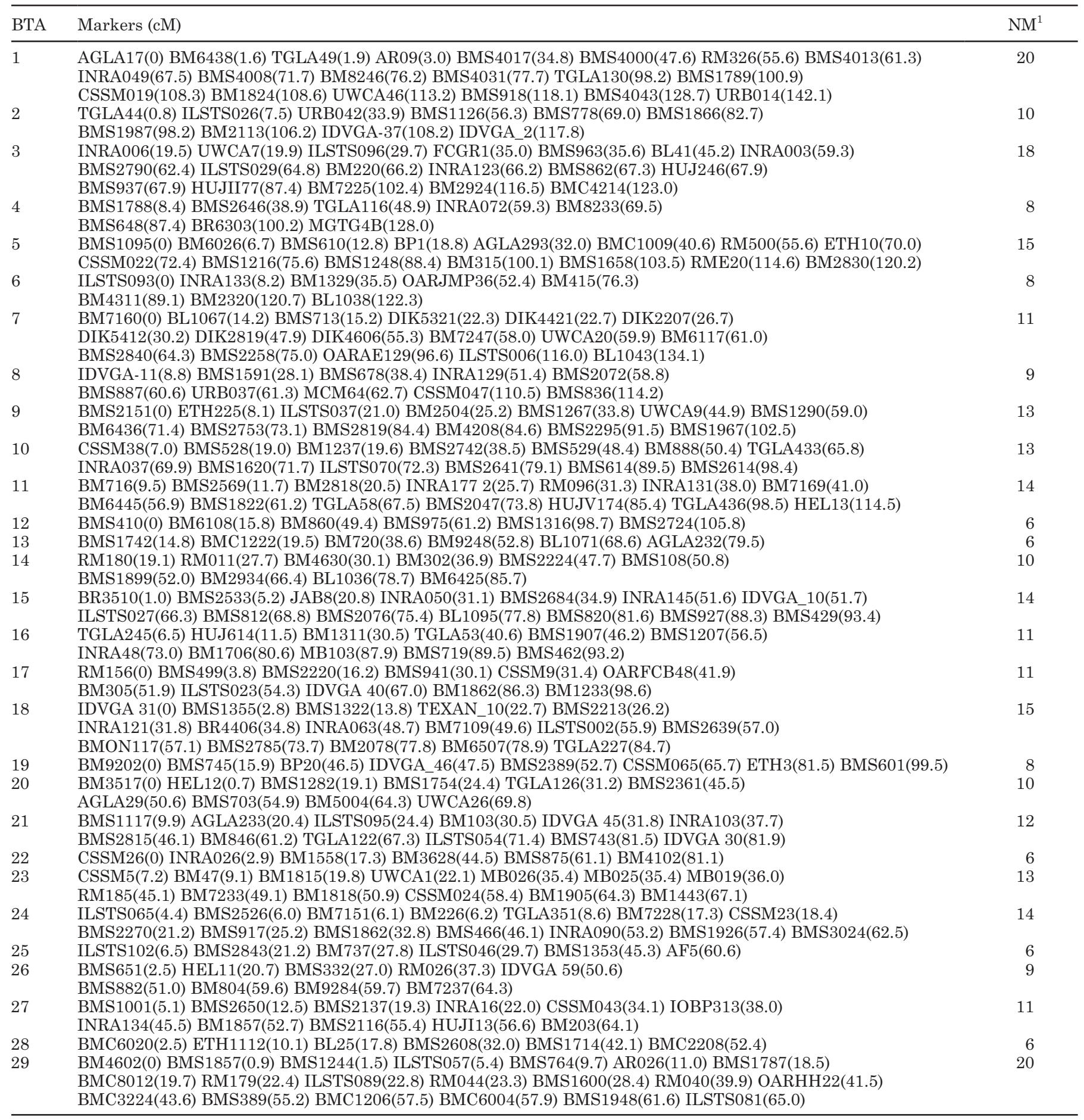

${ }^{1} \mathrm{NM}=$ no. of markers.

as a binary trait indicating whether the cow was assessed and treated for mastitis by a veterinarian in the relevant period. Monthly milkings from first parity were used to calculate SCS in the period from 10 to 180 $\mathrm{d}$ after first calving. Fore udder attachment (UA) and udder depth (UD) were assessed by trained classifiers on a scale from 1 to 9 in first parity. In the scoring system for UA, 1 is defined as loose and 9 as strong, whereas for UD, 1 is defined as deep and 9 as shallow. For milk production traits, the official breeding values 
index was used directly (Danish Cattle Federation, 2006).

\section{Yield Traits}

For each of the traits milk yield, protein yield, and fat yield, a single-trait index (MI, PI, and FI) was calculated using a repeatability model over the first 3 lactations (http://www-interbull.slu.se/national_ges_info2/ framesida-ges.htm). The number of records was 2,017 for SCS and 2,037 for milk and udder conformation traits.

\section{QTL Analysis}

A series of analyses was performed. Initially, the udder health traits were analyzed with a multipoint regression approach for across- and within-family analysis. For chromosomes where chromosome-wise significance was obtained in across-family analysis for clinical mastitis, further analyses were performed. First, yield traits were analyzed with regression models. Second, 2 trait models were fitted using a variance component method for combinations of traits that were significant on these chromosomes. The models fitted were designed to distinguish if the identified QTL was most likely 1 QTL affecting both traits (pleiotropy) or 2 linked QTL, each affecting 1 trait.

Regression Analysis. Population allele frequencies at the markers were estimated from the sons' maternally inherited chromosomes and grandsire chromosomes by using an expectation-maximization (EM) algorithm. Allele frequencies were subsequently assumed known without error. Phase in the sires was determined based on offspring marker types and subsequently assumed known without error. Segregation probabilities at each map position were calculated using information from all markers on the chromosome simultaneously and applying Haldane's mapping function (Haldane, 1919). When it was not possible to distinguish unambiguously whether an allele was inherited from the sire or the dam, the allele frequencies were used to calculate the segregation probabilities. Phenotypes were regressed onto the segregation probabilities. Chromosome-wise significance thresholds were calculated using permutation tests performing 1,000 permutations (Churchill and Doerge, 1994). A chromosome-wise significance level of $5 \%$ was considered significant. In addition, genome-wise false discovery rates (FDR) were estimated for each QTL using the method of Storey and Tibshirani (2003) as implemented in the qvalue package version 1.1 in the statistical package $\mathrm{R}$ (http://cran.r-project. org/web/packages/qvalue/).
Multi-Trait Analysis. For chromosomes affecting clinical mastitis and at least 1 more trait, a multitrait analysis was performed to compare whether the data were better described by a single QTL affecting both traits or by 2 linked QTL each affecting 1 trait. Description of those models can be found in Lund et al., (2003); however, in the present study, we do not include linkage disequilibrium information.

The pleiotropic and linked QTL models can be written as

$$
\mathbf{y}=\mathbf{X} \boldsymbol{\beta}+\mathbf{Z u}+\sum_{\mathrm{i}-1}^{\mathrm{nqtl}} \mathbf{W q}_{\mathbf{i}}+\mathbf{e}
$$

where $\mathbf{y}$ is an $\mathrm{n} \times \mathrm{t}$ vector of observations on $t=(1,2)$ traits and $\mathrm{n}$ animals; $\mathbf{X}$ is a design matrix; $\boldsymbol{\beta}$ is a vector of fixed effects; $\mathbf{Z}$ is a matrix relating records to individuals; $\mathbf{u}$ is a vector of additive polygenic effects; $\mathbf{W}$ is a matrix relating each individual's record to its QTL effect; $\mathbf{q}_{\mathbf{i}}$ is a vector of additive QTL effects corresponding to the ith QTL; and $\mathbf{e}$ is a vector of residuals. The number of QTL, nqtl, is either 1 or 2 . The random variables u, q, and e are assumed multivariate normally distributed and mutually uncorrelated. Specification of pleiotropic and linked QTL models can be seen in Lund et al. (2003). The variance components were estimated using the average information REML algorithm (Jensen et al., 1997) implemented in the software package DMU (Madsen et al., 2006). The restricted likelihood was maximized with respect to the variance components associated with the random effects in the model. Maximizing a sequence of restricted likelihoods over a grid of specific positions yielded a profile of the restricted likelihood for the QTL position.

To obtain computational efficiency and stability, an exhaustive search for linked QTL was avoided by fitting the linked QTL model in maximal likelihood estimates of positions given by the corresponding single trait models. The pleiotropic models were run to cover the region spanning the 2 positions of the linked QTL model.

\section{Model Selection Between Pleiotropic and Linked QTL Models}

The pleiotropic and linked QTL models cannot be compared using likelihood ratio tests because the models are not nested. Therefore, the Bayesian information criterion (BIC; Schwarz, 1978; Kass and Raftery, 1995) was used to evaluate which model was superior. The 2 models incorporate the same number of parameters and, consequently, the BIC simplifies to 


$$
2 \log \left[\frac{p\left(y \mid \hat{\theta}_{\text {linkage }}, \text { Model }_{\text {linkage }}\right)}{p\left(y \mid \hat{\theta}_{\text {pleiotropy }}, \text { Model }_{\text {pleiotropy }}\right)}\right] .
$$

If the 2 models are assumed equally likely a priori, the result using this criterion is an approximation to the posterior probability of the pleiotropic model relative to the posterior probability of the linked QTL model (Bayes factor). Another less formal criterion used to indicate which model is more likely, is the estimated correlation between QTL effects on the 2 traits $\left(\mathbf{r}_{\mathbf{Q} 12}\right)$ from the pleiotropic model. The rationale behind using $\mathrm{r}_{\mathrm{Q} 12}$ is that if the 2 traits are under influence of a biallelic pleiotropic QTL, the true value of $\mathrm{r}_{\mathrm{Q} 12}$ will be 1 .

\section{RESULTS}

\section{Regression Analysis}

From the across-family analyses of the udder health and conformation traits CM1,CM2, CM3, SCS, UD, and UA, 23 QTL were identified using a 5\% chromosome-wise significance level across families (Table 2). The genome-wise FDR ranged from 0.001 to 0.102 . The QTL were found on 15 chromosomes, of which 6 affected clinical mastitis. Only 2 chromosomes reached significance for CM in more than 1 parity. Significant associations with SCS were found for 8 regions. From these, 2 were in regions (BTA5 and BTA6) that were also found to affect CM, whereas the remaining 6 chromosomes gave significant associations to SCS without affecting CM. The trait UD was affected by 5 chromosomes. Of these chromosomes, 2 also affected SCS, but none of them affected CM. The trait UA was affected by 2 chromosomes: BTA13 also showed an effect on SCS and BTA26 showed an effect on CM.

From the 6 chromosomes hosting QTL associated with CM, 3 of them were significantly associated with correlated traits: BTA5 was associated with SCS and FI, BTA6 with SCS, and BTA26 with MI, FI, UA, and UD.

\section{Pleiotropy vs. Linkage}

In situations where a chromosomal region was found to affect clinical mastitis and at least 1 of the correlated traits, it was tested in 2-trait models. This was done to determine whether a model with 1 pleiotropic model affecting both traits or 2 linked QTL each affecting 1 trait was more probable. The multi-trait models gave some tendencies but generally not highly conclusive evidence to distinguish between linkage and pleiotropy of different QTL (Table 3). The strongest result was on BTA5 where the pleiotropic model for CM2 and CM3 was 1,820 times more likely than a linked QTL model. For the remaining chromosomes, the direct model comparisons were inconclusive.

On BTA5, 2-trait models were run between CM2, CM3, SCS, and FI. The most likely situation was that a pleiotropic QTL affects CM2, CM3, and SCS, whereas a linked QTL is affecting FI. This interpretation is based in part on the evidence from Bayes factors, which for all 2-trait combinations of CM1, CM2, and SCS show that a pleiotropic model had greater posterior probability. The evidence is particularly strong for CM1 and CM2. For models including FI, the linkage hypothesis was generally more probable. In addition, the estimated distance between QTL in the 2-trait linkage models were generally greater for combinations including FI (24 to $46 \mathrm{cM}$ ) compared with models between CM1, CM2, and SCS (3.9 to 14.3).

On BTA6, the correlation between QTL effects on SCS and CM2 from a modeled pleiotropic effect was near unity, and in the linkage model, the estimates of the 2 QTL positions were close. This result is in concordance with a biallelic pleiotropic QTL, which may therefore be regarded as the most likely situation.

On BTA9, the most probable model was a pleiotropic QTL affecting CM1 and CM2 at approximately $8 \mathrm{cM}$. The evidence for pleiotropy of the QTL is given in part by limited evidence from the Bayes factors and in part from the fact that the correlation between QTL effects on CM1 and CM2 was unity in the pleiotropic model.

The multi-trait analyses for BTA26 did not provide useful information to distinguish between models. All Bayes factors were in the range between 0.77 and 10.0 and correlations were mostly intermediate. Also, no clear pattern was found among the different 2-trait models.

\section{DISCUSSION}

Significant effects on the risk of being diagnosed with $\mathrm{CM}$ in 1 or more of the first 3 lactations (CM1, CM2, and CM3) were found on 6 chromosomal regions. Out of these regions, only 2 affected the trait in more than 1 lactation. This result was less than expected because the genetic correlations between clinical mastitis in the first, second, and third lactations have been estimated to be very high. To some degree, this result may be because some sons did not have phenotypes for CM3. In 5 of the younger grandsires, many of their sons did not yet have information from the third lactation of their daughters. The lack of consistency probably reflects a lack of power to detect QTL that affect CM, which is a result of the very low heritability. The low heritability results in EBV with relatively low reliabilities and is more pronounced for CM3 because bulls have 
Table 2. Probability values for joint chromosome-wise tests and genome-wise false discovery rates (FDR) using across-family regression models for clinical mastitis in first, second, and third lactation (CM1, CM2, and CM3), SCS, udder depth (UD), and fore udder attachment $(\mathrm{UA})^{1}$

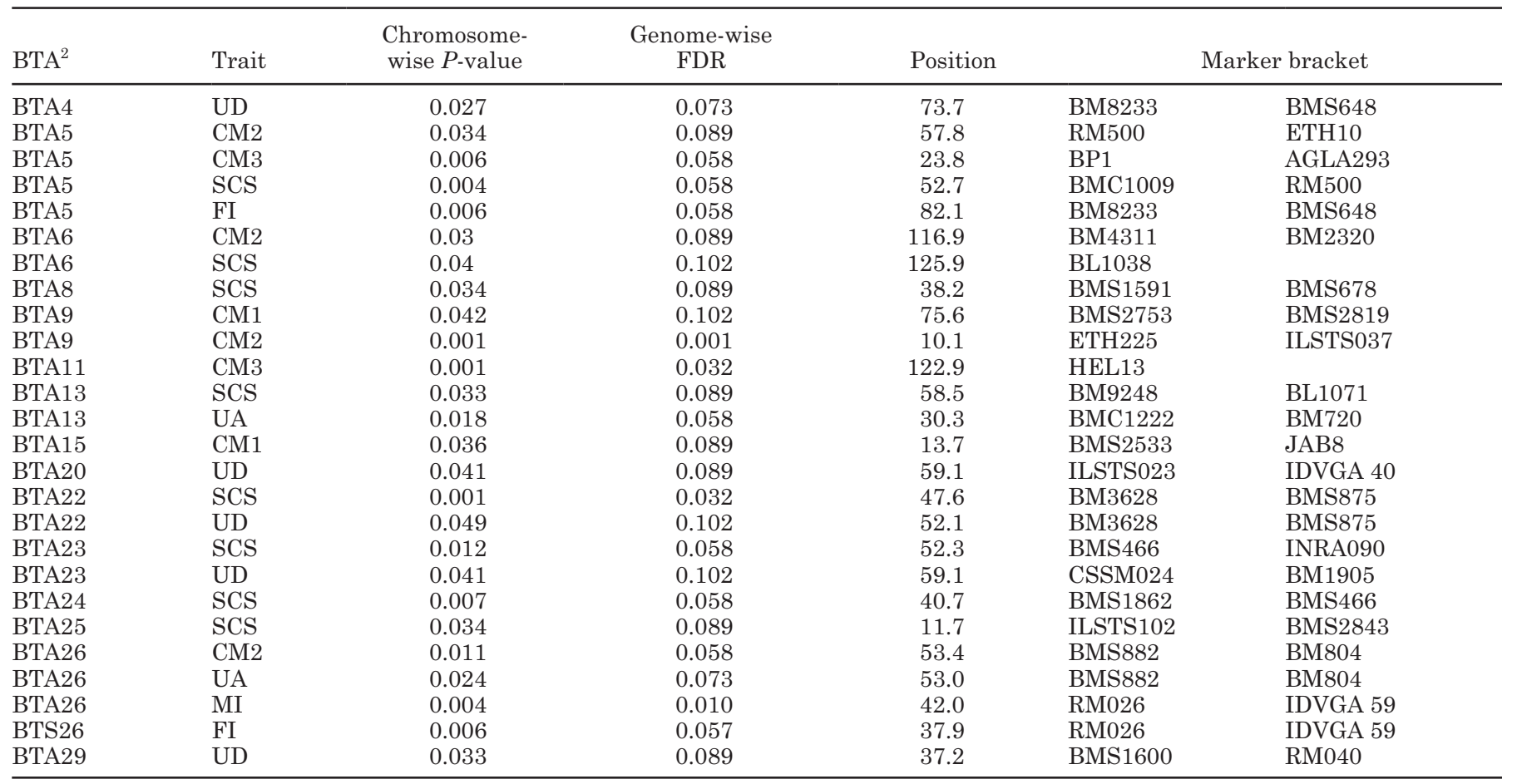

${ }^{1}$ For chromosomes with significant effects on clinical mastitis significance of QTL affecting milk yield index (MI), protein yield index (PI), and fat yield index (FI) are indicated.

${ }^{2} \mathrm{BTA}=$ Bos taurus autosome.

fewer daughters with third-lactation observations than first- and second-lactation observations. Confidence in a particular result, therefore, will increase if the same region affects other genetically correlated traits. From the 6 chromosomes affecting CM in our study, BTA5, BTA6, BTA9, and BTA26 affected highly correlated traits.

Somatic cell score is moderately correlated to CM and to some degree expresses the same response to infection by mastitis pathogens. From the 6 regions affecting CM, 2 (BTA5 and BTA6) also affected SCS. This total is less than expected based on the moderate genetic correlation between the traits. Some evidence has been reported in the literature that the remaining chromosomes may affect SCS. Significant effects were found by Boichard et al. (2003) and Holmberg and Andersson-Eklund (2004) on BTA9; by Holmberg and Andersson-Eklund (2004), Schulman et al. (2004), and Zhang et al. (1998) on BTA11; by Boichard et al. (2003) on BTA15; and by Zhang et al. (1998) on BTA26. However, our study found very little evidence except for BTA15, which, with a $P$-value of 0.1 , is approaching significance. To some degree, the lack of coincidence may be explained by differing effects of a QTL over lactations. For instance, the QTL on BTA11 seemingly had very little effect in first lactation, where it was not detected for either CM1 or SCS. The $P$-values decrease for each lactation for this QTL, reaching significance in the third lactation.

For BTA5, the result already appeared to be quite reliable, as the putative QTL affected CM in both the second and third lactations. Chromosome 5 is the only chromosome with substantial evidence from the Bayes factors to distinguish between pleiotropy and linkage. The best supported model is with 1 QTL affecting CM2, CM3, and SCS and a linked QTL affecting FI. The phase between the 2 QTL is such that individuals carrying the positive QTL allele for CM have a high probability to carry the negative QTL allele for FI. However, according to our position estimates, the 2 QTL are about 30 $\mathrm{cM}$ apart. This distance is sufficiently large to select for recombinant individuals that are positive for the QTL affecting CM as well as the QTL affecting FI. By doing so, one should be able to alter the genetic correlation between the traits to be less antagonistic. Bos taurus autosome 5 has been found to be significant for SCS in an overlapping region in North American HolsteinFriesians (Heyen et al., 1999).

There was insufficient evidence to distinguish pleiotropy from linkage on BTA6. The small distance 
Table 3. Results from 2-trait pleiotropic and linkage models ${ }^{1}$

\begin{tabular}{|c|c|c|c|c|}
\hline Chromosome $^{2}$ & Traits & $\begin{array}{c}\text { QTL } \\
\text { correlation } \mathrm{r}_{\mathrm{Q} 12}\end{array}$ & $\begin{array}{c}\text { Genetic map } \\
\text { distance between } \\
\text { QTL locations }(\mathrm{cM})\end{array}$ & $\begin{array}{l}\text { Bayes } \\
\text { factor }\end{array}$ \\
\hline BTA5 & $\begin{array}{l}\text { SCS/FI } \\
\text { SCS/CM2 } \\
\text { SCS/CM3 } \\
\text { FI/CM2 } \\
\text { FI/CM3 } \\
\text { CM2/CM3 }\end{array}$ & $\begin{array}{l}0.74 \\
0.69 \\
0.71 \\
0.78 \\
0.39 \\
0.97\end{array}$ & $\begin{array}{r}30 \\
6 \\
16 \\
24 \\
46 \\
22\end{array}$ & $\begin{array}{r}0.07 \\
9.1 \\
4.5 \\
1.3 \\
0.1 \\
1,820.5\end{array}$ \\
\hline BTA9 & CM1/CM2 & 1.0 & 34 & 3.7 \\
\hline BTA26 & $\begin{array}{l}\text { UA/FI } \\
\text { UA/CM2 } \\
\text { UD/MI } \\
\text { FI/CM2 } \\
\text { FI/MI } \\
\text { MI/CM2 }\end{array}$ & $\begin{array}{r}-0.12 \\
-0.72 \\
0.15 \\
0.31 \\
0.46 \\
\mathrm{NC}^{3}\end{array}$ & $\begin{array}{r}12 \\
2 \\
8 \\
14 \\
4 \\
10\end{array}$ & $\begin{array}{c}1.0 \\
10.0 \\
1.0 \\
0.77 \\
3.7 \\
\mathrm{NC}\end{array}$ \\
\hline
\end{tabular}

${ }^{1}$ Correlations between QTL effects on the 2 traits in the pleiotropic model, distance between peaks in a 2-QTL linkage model, and the Bayes factor of a pleiotropic model over a linkage model.

${ }^{2} \mathrm{BTA}=$ Bos taurus autosome.

${ }^{3} \mathrm{NC}$ means nonconvergence for the REML procedure.

between the 2 positions in the linkage model and a high correlation of 0.99 between QTL effects on SCS and CM3 indicate that it may be a pleiotropic QTL. Yield traits were not included in multi-trait analyses on BTA6, even though there is strong evidence from the literature that this chromosome affects yield traits. In Kučerová et al. (2006), which is based in part on the same data as the present paper, significant effects were also found on BTA6. However, this was only for protein percentage and fat percentage in single-trait analyses or similarly for protein and fat yield when adjusted for milk yield in multi-trait models. In the current paper, we only analyzed the yield traits that are currently selected for and only in single-trait models, which were not significant. On BTA9, little evidence was found to distinguish linkage from the pleiotropic models. However, the best supported model was a pleiotropic QTL affecting CM1 and CM2 at approximately $8 \mathrm{cM}$. The ability to distinguish between pleiotropic and linkage models is related to the number of informative markers between any linked QTL. In general, only a very limited number of informative markers were available between the estimated QTL positions from single trait models. With an average distance of $8.6 \mathrm{cM}$ between markers, and an average distance at about $17 \mathrm{cM}$ estimated in 2-trait linkage models (Table 3 ), there would rarely be more than one informative marker between the putative QTL. This is probably the limiting factor in our ability to separate the models.

For SCS, 8 of the joint family QTL analyses were found to be significant chromosome-wide. Among these
QTL, only 2 regions affected CM. This total is less than expected given the relatively high genetic correlation between the traits. The genetic correlation between SCS and CM is in the range of 0.48 to 0.56 (Danish Cattle Federation, 2006). This may reflect that SCS is measured in the first $180 \mathrm{~d}$ only, whereas cases of CM are included for $305 \mathrm{~d}$. Therefore, cases after 180 $\mathrm{d}$ will not result in increased SCS. Generally, however, there are only a few cases of CM in the later part of the lactation, so it is not expected to be a major reason. Another reason could be a relatively low power to detect QTL for clinical mastitis. As an example, on BTA22, 3 families were segregating (chromosome-wise 5\% significance within families) for SCS, which results in a significant combined effect across families. However, on CM2 there are also 3 families segregating, and 2 of the families are the same as for SCS. This increases the credibility of the QTL and indicates that it is less likely to get significant results for CM. Nevertheless, in populations where only SCS is available, it is not possible to evaluate which QTL affect CM and which QTL only affect SCS. As we are analyzing for both CM and SCS, the present analyses may help to indicate if SCS QTL from the literature can also be expected to affect CM. For example, BTA5 has previously been found to affect SCS in North American Holstein-Friesians. In our study, a pleiotropic QTL affecting SCS and CM was found in this region, which indicates that the QTL previously found may indeed affect CM. The results on BTA23 confirm the segregation of SCS QTL from several studies (Reinsch et al., 1998; Heyen et al., 1999; 
Klungland et al., 2001; Ashwell et al., 2004). However, for this QTL, there is no evidence that it would affect CM. In our study, none of the families segregating for SCS also segregated for a CM QTL. Also, there were no more significant family results than what would be expected under the null hypothesis of no segregating QTL.

According to our results, we can expect that markers on chromosomes $6,9,11$, and 15 can be used to perform marker-assisted selection on $\mathrm{CM}$ without an associated negative genetic progress on milk yield, because no effects were detected on the milk traits. The exception may be chromosome 6 , where there is evidence from several populations for QTL affecting milk production traits (Khatkar et al., 2004). However, the reason for not including yield traits in the multi-trait analyses of the present study is that, according to past studies of our material, only tests for QTL affecting the percentage traits were highly significant, whereas the yield traits were not affected (Kučerová et al., 2006). Chromosome 5 affected milk yield as well as clinical mastitis, in which case the relationship between the 2 traits has to be taken into account. In this case, inconclusive evidence was found that the most probable genetic determinism was 2 different QTL, 1 affecting mastitis traits and 1 affecting yield traits, linked with some distance between them.

Assuming that this is the case, it would be possible to select individuals that inherit haplotypes with a desirable linkage phase between the 2 loci. However, the evidence for 2 linked QTL rather than 1 pleiotropic QTL was not very strong due to few informative markers between the supposing linked QTL. Using a much denser map and including information from linkage disequilibrium is probably needed to reach strong conclusions in this respect.

In the Nordic system, selection is performed to reduce clinical mastitis; SCS is only used as correlated information source. However, SCS is better at measuring subclinical cases, which are responsible for a substantial part of the economic loss due to mastitis. Therefore, an economic weight should probably be given to SCS. If this were the case, the QTL on chromosomes 8, 13, 22, 23,24 , and 25 that were found to affect SCS only could be used directly in the selection index.

\section{ACKNOWLEDGMENTS}

We thank the Danish Cattle Federation for providing phenotypic data. This project was funded by FREM98 DJF: New technologies in farm animal breeding and j.no. 34016503 136: DNA based selection to improve disease resistance, fertility, calf survival and production in Danish dairy cattle from the Danish Directorate for Food, Fisheries and Agri Business j.no. 3401-0400853.

\section{REFERENCES}

Ashwell, M. S., D. W. Heyen, T. S. Sonstegard, C. P. Van Tassell, Y. Da, P. M. VanRaden, M. Ron, J. I. Weller, and H. A. Lewin. 2004. Detection of quantitative trait loci affecting milk production, health, and reproductive traits in Holstein cattle. J. Dairy Sci. 87:468-475.

Boichard, D., C. Grohs, F. Bourgeois, F. Cerqueira, R. Faugeras, A. Neau, R. Rupp, Y. Amigues, M. Y. Boscher, and H. Leveziel. 2003. Detection of genes influencing economic traits in three French dairy cattle breeds. Genet. Sel. Evol. 35:77-101.

Churchill, G. A., and R. W. Doerge. 1994. Empirical threshold values for quantitative trait mapping. Genetics 138:963-971.

Danish Cattle Federation. 2006. Principles of Danish Cattle Breeding. 8th ed. http://www.lr.dk/kvaeg/diverse/principles.pdf Accessed Jan. 15, 2007.

Haldane, J. B. S. 1919. The combination of linkage values and the calculation of distances between the loci of linked factors. J. Genet. 8:299-309.

Heringstad, B., G. Klementsdal, and J. Ruane. 2000. Selection for mastitis resistance in dairy cattle: A review with focus on the situation in the Nordic countries. Livest. Prod. Sci. 64:95-106.

Heyen, D. W., J. I. Weller, M. Ron, M. Band, J. E. Beever, E. Feldmesser, Y. Da, G. R. Wiggans, P. M. Vanraden, and H. A. Lewin. 1999. A genome scan for QTL influencing milk production and health traits in dairy cattle. Physiol. Genomics 1:165-175.

Holmberg, M., and L. Andersson-Eklund. 2004. Quantitative trait loci affecting health traits in Swedish dairy cattle. J. Dairy Sci. 87:2653-2659.

Jensen, J., E. Mantysaari, P. Madsen, and R. Thompson. 1997. Residual maximum likelihood estimation of (co)variance components in multivariate mixed linear models using average information. J. Indian Soc. Agric. Stat. 49:215-236.

Kass, E. R., and A. E. Raftery. 1995. Bayes factors. J. Am. Stat. Assoc. 90:773-795.

Khatkar, M. S., C. T. Peter, T. Imke, and W. R. Herman. 2004. Quantitative trait loci mapping in dairy cattle: Review and metaanalysis. Genet. Sel. Evol. 36:136-190.

Klungland, H., A. Sabry, B. Heringstad, H. G. Olsen, L. Gomez-Raya, D. I. Vage, I. Olsaker, J. Odegard, G. Klemetsdal, N. Schulman, J. Vilkki, J. Ruane, M. Aasland, K. Ronningen, and S. Lien. 2001. Quantitative trait loci affecting clinical mastitis and somatic cell count in dairy cattle. Mamm. Genome 12:837-842.

Kučerová, J., M. S. Lund, P. Sørensen, G. Sahana, B. Guldbrandtsen, V. H. Nielsen, B. Thomsen, and C. Bendixen. 2006. Multi-trait QTL mapping for milk production traits in Danish Holstein cattle. J. Dairy Sci. 89:2245-2256.

Kuhn, C., J. Bennewitz, N. Reinsch, N. Xu, H. Thomsen, C. Looft, G. A. Brockmann, M. Schwerin, C. Weimann, S. Hiendleder, G. Erhardt, I. Medjugorac, M. Forster, B. Brenig, F. Reinhardt, R. Reents, I. Russ, G. Averdunk, J. Blumel, and E. Kalm. 2003. Quantitative trait loci mapping of functional traits in the German Holstein cattle population. J. Dairy Sci. 86:360-368.

Longeri, M., M. Polli, M. G. Strillacci, A. B. Samorè, and M. Zanotti. 2006. Quantitative trait loci affecting the somatic cell score on chromosomes 4 and 26 in Italian Holstein cattle. J. Dairy Sci. 89:3175-3177.

Lund, M. S., J. Jensen, and P. H. Petersen. 1999. Estimation of genetic and phenotypic parameters for clinical mastitis, somatic cell production deviance, and protein yield in dairy cattle using Gibbs sampling. J. Dairy Sci. 82:1045-1051.

Lund, M. S., P. Sørensen, B. Guldbrandtsen, and D. A. Sorensen. 2003. Multi-trait fine mapping of quantitative trait loci using combined linkage disequilibria and linkage analysis. Genetics 163:405-410.

Madsen, P., P. Sørensen, G. Su, L. H. Damgaard, H. Thomsen, and R. Labouriau. 2006. DMU-A package for analyzing multivariate 
mixed models. CD Commun 27-11 in Proc. 8th World Congr. Genet. Appl. Livest. Prod., Belo Horizonte, MG, Brazil.

Pösö, J., and E. A. Mantysaari. 1996. Relationships between clinical mastitis, somatic cell score, and production in the first three lactations of Finnish Ayshire. J. Dairy Sci. 79:1284-1291.

Reinsch, N., H. Thomsen, C. Looft, E. Kalm, S. Grupe, C. Kuhn, M. Schwerin, B. Leyhe-Horn, S. Hiendleder, G. Erhardt, I. Medjugorac, I. Russ, M. Forster, B. Brenig, R. Reents, and G. Averdunk. 1998. First results on somatic cell counts loci from the ADR bovine mapping project. Pages 426-428 in Proc. 6th World Congr. Genet. Appl. Livest. Prod., Armidale, Australia. University of New England, Armidale, Australia.

Sahana, G., D. J. de Koning, B. Guldbrandtsen, P. Sørensen, and M. S. Lund. 2006. The efficiency of mapping of quantitative trait loci using cofactor analysis in half-sib design. Genet. Sel. Evol. 38:167-182.

Schrooten, C., M. C. A. M. Bink, and H. Bovenhuis. 2004. Whole genome scan to detect chromosomal regions affecting multiple traits in dairy cattle. J. Dairy Sci. 87:3550-3560.

Schrooten, C., H. Bovenhuis, W. Coppieters, and J. A. M. van Arendonk. 2000. Whole genome scan to detect quantitative trait loci for conformation and functional traits in dairy cattle. J. Dairy Sci. 83:795-806.

Schulman, N. F., S. M. Viitala, D. J. de Koning, J. Virta, A. MäkiTanila, and J. Vilkki. 2004. Quantitative trait loci for health traits in Finnish Ayrshire cattle. J. Dairy Sci. 87:443-449.
Schwarz, G. 1978. Estimating the dimension of a model. Ann. Stat. 6:461-464.

Simianer, H., H. Solbu, and L. R. Schaeffer. 1991. Estimated genetic correlations between disease and yield traits in dairy cattle. J. Dairy Sci. 74:4359-4365.

Storey, J. D., and R. Tibshirani. 2003. Statistical significance for genome-wide experiments. Proc. Natl. Acad. Sci. USA 100:94409445.

Sugimoto, M., A. Fujikawa, J. E. Womack, and Y. Sugimoto. 2006 Evidence that bovine forebrain embryonic zinc finger-like gene influences immune response associated with mastitis resistance. Proc. Natl. Acad. Sci. USA 103:6454-6459.

Weller, J. I., Y. Kashi, and M. Soller. 1990. Power of daughter and granddaughter designs for determining linkage between marker loci and quantitative trait loci in dairy cattle. J. Dairy Sci. 73:2525-2537.

Zhang, Q., D. Boichard, I. Hoeschele, C. Ernst, A. Eggen, B. Murkve, M. Pfister-Genskow, L. A. Witte, F. E. Grignola, P. Uimari, G. Thaller, and M. D. Bishop. 1998. Mapping quantitative trait loci for milk production and health of dairy cattle in a large outbred pedigree. Genetics 149:1959-1973. 